\section{E-MRS to Hold 1995 Spring Meeting in France}

The European Materials Research Society (E-MRS) will hold its 1995 Spring Meeting in Strasbourg, France, May 22-26. Full-length papers will be published in a Proceedings Volume by Elsevier/North Holland. Submitted papers will be refereed. The conference language is English.

The following 14 symposia are planned: A. Microstructuring and Microsystems

B. Materials for Science: Functional

Nanoscaled Structures

C. Pushing the Limits of Ion Beam

Processing-From Engineering to Atomic Scale Issues

D. Purification, Doping and Defects in

II- VI Materials

E. Structure and Properties of Metallic

Thin Films and Multilayers

F. Third International Conference on Laser Alation-COLA'95

G. Atomic Scale Characterization and Simulation of Materials and Processes H. Advanced Deposition Processes and Characterization of Protective Coatings I. Porous Silicon: Material, Technology and Devices

J. Correlated Effects in Atomic and

Cluster Ion Bombardment and

Implantation

K. Fullerenes: From New Molecules to

New Materials

L. 6th International Symposium on

Silicon Molecular Beam Epitaxy

M. New Prospects on Electronic

Properties of Organic Materials

N. Carbon, Hydrogen, Nitrogen and

Oxygen in Silicon and in Other Elemental Semiconductors

Abstracts (confined to an area of 17.5 $\mathrm{cm}$ wide by $23 \mathrm{~cm}$ long) should be submitted to one of the chairpersons of the respective symposium.

The deadline for abstract submission is March 1, 1995. For information on the symposia chairs, and for further general information about the conference, contact P. Siffert, Conference Secretariat, E-MRS 1995 Spring Meeting, BP 20,67037 Strasbourg Cedex 2, France; phone (33) 881065 43; fax (33) 881062 93; e-mail: BRUTT@FRCPN11. IN2P3.FR

News about IUMRS conferences and other activities should be sent to:

MRS Bulletin

Materials Research Society

9800 McKnight Road

Pittsburgh, PA 15237-6006

Fax (412) 367-4373 modeling Program Chairs: FAX (304) 293-8155
Travel Arrangements and Registration

Citizens having passports from certain countries need a visa to enter France. For visa assistance, contact Madeleine Cobut, E-MRS, BP 20, 67037 Strasbourg Cedex 2, France; phone: (33) 881063 72; fax: (33) 88 106343.

Registration fees paid before May 8, 1995 is 2 300,00 French Francs (FF) net, and after May 8, 1995, 2 600,00 FF net. The fees include the Proceedings of one symposium, breaks, lunches, local transportation, E-MRS membership for one year, and 12 issues of the MRS Bulletin. Students wishing to obtain the special "student fare" must give evidence of their university registration. The student fare paid before May 8,1995 is $1200,00 \mathrm{FF}$ net, and after May 8, 1995, 1500,00 FF net. If a purchase order is sent to cover the registration fees, the highest registration rate will be invoiced by E-MRS.

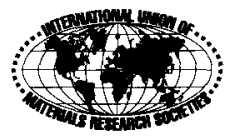

\section{Attending the 1995 MRS Spring Meeting?}

\section{CURRENT MRS MEMBERS PAY A LOWER REGISTRATION FEE.}

\begin{abstract}
All MRS Fall and Spring Meeting registrations now include a complimentary membership benefit. And as long as you keep your membership current, you'll always pay a lower registration fee.
\end{abstract}

Questions? Contact MRS Member Services, 412/367-3004 x402; fax 412/367-4373; e-mail INFO@MRS.ORG.

\title{
Announcement
}

Fifth Conference on Computational Research on Materials May 3, 4, and 5, 1995

Lakeview Resort and Conference Center Morgantown, WV Abstract Deadline - April 5, 1995

Join leading material researchers from universities, industry, and national laboratories in assessing the aims and latest developments in computational materials research:

- industrial applications of computational materials modeling

- atomistic and continuum modeling for the design of both structural and electronic materials systems

- the role of highly parallel computing for specific problems

- linking experimental verification to atomistic and continuum

- the national materials research agenda and materials modeling

B.R.Cooper-WVU, H.Kuhn-Concurrent Technologies Corp., R.A.LeSar-Los Alamos Nat. Lab, S.T.Pantelides-Vanderbilt U.

For more information, contact:

Martha Spenger, WV EPSCoR, West Virginia University, PO Box 6845, Morgantown, WV 26506-6845, Phone (304) 293-8274, 